\title{
Can recurrences be predicted in craniopharyngiomas? $\beta$-catenin coexisting with stem cells markers and p-ATM in a clinicopathologic study of 45 cases
}

Elia Guadagno ${ }^{1 *}$, Oreste de Divitiis², Domenico Solari², Giorgio Borrelli', Umberto Marcello Bracale ${ }^{3}$, Alberto Di Somma², Paolo Cappabianca ${ }^{2}$ and Marialaura Del Basso De Caro ${ }^{1}$

\begin{abstract}
Background: Recurrence is a common feature of craniopharyngiomas, benign tumors that origin from squamous epithelial remnants of Rathke's pouch- arising at any segment of its whole course. There are two histotypes, showing different morphology and clinical behavior: adamantinomatous(adaCP) and papillary (papCP). An univocal strategy of management has not yet been defined, being considered the combination of surgery and radiotherapy the most effective, especially in case of incomplete resection. Therefore, the identification of factors influencing the biological and clinical behaviour is of paramount importance.

$\beta$-catenin is a cell-cell adhesion protein, whose nuclear localization has been linked to the pathogenesis of adaCP: its nuclear accumulation is associated to the presence of a tumor stem cell subpopulation. The latter is made of cells capable of self-renewal, hence believed to be responsible of recurrence, metastases and resistance to therapy in all tumors.

ATM is a kinase activated by autophosphorylation (p-ATM) upon DNA double-strand breaks. It is involved not only in DNA repair, but also in tumor migration and invasiveness. Its expression may have prognostic implications in many neoplastic diseases.
\end{abstract}

Methods: In this study, we measured the immunohistochemical expression of $\beta$-catenin, stem cell markers (CD133, CD166), Ki67 and pATMin 45 craniopharyngiomas and correlated it with clinicopathologic features.

Results: Statistical analysis revealed strong correlation of $\beta$-catenin with recurrence $(p=0.0039)$, Ki67 ( $p=0.0011$, $r=0.4903)$ and CD166 ( $p=0.0002, r=0.6218)$. A slight tendency to a higher expression of $\beta$-catenin was recorded for adaCP rather than papCP ( $p=0.0895)$.Fisher's exact test showed that CD166 was significantlyrelated with recurrence $(p=0.0040)$. Furthermore, cytoplasmic pATM was more expressed in adaCPs $(p=0.0470)$, compared to papCPs that displayed a more evident nuclear signal $(p=0.0313)$ instead.

Conclusions: Backing upon these data, we could weigh in on the need of identifying $\beta$-catenin and CD166 as prognostic markersthat could be useful in predicting thebiologicalbehavior, as recurrence risk incraniopharyngiomas. The final goal is to drew up a prognostic algorithm to be of aid in the planning of an appropriate treatment strategy. Furthermore, our findings demonstrate that PATM could be used as additional distinction-marker between the two histotypes.

Keywords: Craniopharyngiomas, $\beta$-catenin, Recurrence, CD166

\footnotetext{
* Correspondence: eliaguadagno84@gmail.com

'Department of Advanced Biomedical Sciences, Pathology Section, University

of Naples Federico II, Via Pansini 5, 80131 Naples, Italy

Full list of author information is available at the end of the article
} 


\section{Background}

Craniopharyngiomas (CPs) are rare benign tumors of the sellar and parasellar region, classified as low histologic grade (WHO grade I) that account for $2-4 \%$ of all intracranial tumors [1]. Two histological subtypes exist, namely adamantinomatous (adaCP) and papillary (papCP), differing for age distribution, frequency, biology and clinical outcome. The former are more frequent, with two peaks of incidence (under 15 years and between 50 and 74 years), and a heavy tendency to infiltrate the surrounding structures (hypothalamic/pituitary axes and optic nerve/chiasma), by finger-like protrusions. On the other side, papCPs are less common and mainly affect adults.

Thus far, the possibility of identifying inner tumor factors influencing the biological and clinical behavior of this "chronic disease" is paramount.

Pathogenesis of $\mathrm{CP}$ accounts on an embryogenic theory for adaCP and a so-called metaplastic for papCP: the adamantinous type arises from remnant cells of the Rathke's pouch, while the latter from adenohypophyseal cells, which underwent to squamous metaplastic changes $[2,3]$. Dysregulation of the $\mathrm{WNT} / \beta$-catenin signaling pathway is involved in the pathogenesis of adaCP: hence the presence of cells that accumulate $\beta$-catenin in the nucleus and cytoplasm and that gather along to form whirl-like structures can be detected. Activating mutations of the beta-catenin gene (exon3 of CTNNB1 gene) can be identified in the majority of adaCPs $[4,5]$, but not in papCPs, nor in other tumors of the sellar region [6]; the vast majority of papCPs harbor the oncogenic BRAF V600E mutation: CTNNB1 and BRAF alterations are mutually exclusive, clonal and specific to each subtype $[7,8]$.

In case of exon3 deletion of CTNNB1 gene, an active form of $\beta$-catenin protein is translated but it lacks the amino acids that allow its phosphorylation and then its degradation, thus resulting in an over-activation of the WNT/ $\beta$-catenin pathway [9].

Studies in mice showed that $\mathrm{WNT} / \beta$-catenin pathway is required for normal pituitary morphogenesis and differentiation. A constitutive activation of this pathway in Rathke's pouch undifferentiated precursor cells is at the base of childhood-onset adaCP, while CTNNB1 mutations in $\beta$-catenin accumulating cell clusters are the cause of adulthood-onset adaCP [10]. Growing evidences showed that cells forming clusters are Sox $2+$ stem cells and that stem cell marker CD133 is co-expressed with $\beta$-catenin in adaCPs [11]. Furthermore, cells showing $\beta$ catenin accumulation displayed low proliferative activity (Ki67).

Complete removal at first surgical attempt has been suggested as the most effective treatment, although itcould eventually determine visual impairment, endocrinological disturbances, and/or hypothalamic disturbances, resulting in impairment of social and behavioral disturbances. However, craniopharyngiomas can recur even after radical resection with a rate of $23 \%$ [2] and, whether subtotal resection has been achieved, the incidence of recurrence is higher [12-16]. The treatment of the primary tumor and of recurrences with different integrated therapeutic approaches may be necessary in order to achieve long-termand, eventually, preserve a good quality of life.

When analyzing the issue of recurrence, the need of defining morphologic (large size, adhesiveness to surrounding vascular or neural structures, tumor consistency), histologic (adamantinomatoushistotype, presence of $\beta$-catenin + cell clusters, peritumoral glial reaction, brain invasion) and/or molecular factors (Ki67 and p53) is crucial to rule out the predictive role [17], but reliable factors are still lacking.

Stem cells represent a small proportion of tumor cells capable of self-renewal and differentiation towards mature cells, hence believed to be responsible of cancer evolution, recurrence, metastases and resistance to chemotherapy and radiation in all tumors [18-21]. CD133, a glycosylated five-transmembrane protein, and CD166, an activated leukocyte cell-adhesion molecule, represent cancer stem cell markers with a negative prognostic role in many solid tumors [22].

ATM is a kinase activated by autophosphorylation (pATM) upon DNA double-strand breaks arising from errors during replication, byproducts of metabolism, chemotherapy or ionizing radiations [23]. ATM expression has been evaluated in many tumor types, finding a different prognostic role in each of them.

The aim of our study was to assess the expression of $\beta$-catenin and compare it with stem cell markers, as CD133 and CD166, with the proliferative index (Ki67 Labeling index) in a quite conspicuous number of craniopharyngiomas. Furthermore, we measured pATM expression in all those cases. The results were then compared with the recurrence rate, in order to evaluate the potential prognostic role of all these factors.

\section{Methods \\ Collective}

Forty five samples of craniopharyngioma were analyzed. They were all obtained as formalin fixed tissue from the archive of the Department of Anatomic Pathology of the Federico II University Hospital of Naples. Patients underwent surgery, with endoscopic endonasaltransphenoidalapproach, at the Department of Neurosurgery of the same hospital. The cases were identified between 1998 and 2015 and the diagnoses were made in accordance with the World Health Organization (WHO) classification (1). Only specimens containing sufficient 
amountsof the respective CP subtype were taken into account. Of each specimen, samples exclusively made of fibro-inflammatory reaction, that is common in this type of pathology, were excluded from this analysis.

For each patient, follow-up data were available and we had a written informed consent to use part of the specimen for scientific and/or research scopes.

\section{Immunohistochemistry}

Four $\mu \mathrm{m}$ sections were used for immunohistochemistry. Sections were dewaxed in xylene, hydrated in graded series of alcohol and subjected to heat-induced antigen retrieval $(10 \mathrm{mM}$ Sodium Citrate, $0.05 \%$ Tween 20, $\mathrm{pH}$ 6.0). After blocking endogenous peroxidase activity, the tissue was incubated with monoclonal antibodies for anti $\beta$-catenin (clone 14, mouse; Roche Ventana, 1:100 dilution), CD166 (clone MOG/07, ab49496, mouse; Abcam, 1:100 dilution), p-ATM (phosphoS1981)(clone ab81292;abcam; 1: 200 dilution) and Ki67 (Clone MIB1, mouse; Dako, 1:100 dilution) and with the polyclonal antibody CD133 (rabbit; Abcam, 1:100 dilution), all for $90 \mathrm{~min}$. Subsequently, the slices were rinsed and incubated with the biotinylated secondary antibody, at room temperature, for $30 \mathrm{~min}$. The bound antibody complexes were stained for 3-5 min or until appropriate for microscopic examination with diaminobenzidine, and they were then counterstained with hematoxylin (30s) and mounted. Appropriate positive controls were chosen: mammary fibromatosis for $\beta$-catenin, normal skin for CD166 and CD133 and normal pancreas for p-ATM. Negative control was obtained by omitting the primary antibody.

\section{Scoring}

All the slices were reviewed by two experienced pathologists (MD, EG), using light microscopy. In discordant cases the slides were re-evaluated on a multi-headed microscope to achieve consensus.

$\beta$-catenin was considered as positive only in case of nuclear staining and a total immunostaining score (IS) was calculated as the product of a Proportion score $(\mathbf{0}=0 \%, \mathbf{1}<10 \%, \mathbf{2}=10-50 \%, \mathbf{3}=51-80 \%, \mathbf{4}>80 \%)$ and an Intensity score $(\mathbf{0}=$ no signal, $\mathbf{1}=$ weak signal, $\mathbf{2}=$ moderate, $\mathbf{3}=$ strong). The same IS was used also for CD133 and CD166 membrane signal. The 3 markers were then divided into two scoring groups, on the base of the IS: absent/low expression (IS $=0-2$ ) and moderate/high expression (IS = 3-12).

For pATM, a different scoring system was adopted because no differences in intensity were noticed. It was based on the proportion of neoplastic cells showing a signal and on its cellular localization $(\mathrm{C}$, cytoplasmic or $\mathrm{N}$, nuclear): $\mathbf{0}=$ absent, $\mathbf{1}=<10 \%, \mathbf{2}=10-30 \%, \mathbf{3}>30 \%$.
For the evaluation of the proliferating index Ki67 (Labeling Index, L.I.), "hot spot" areas were chosen and an average of the values on 5 adjacent fields (at least 500 neoplastic cells) was calculated: normally highly proliferating areas were excluded, namely basal cells. A cut-off of $5 \%$ was identified because the median value was of $6 \%$.

In some cases not all the markers could be tested because of tissue exhaustion.

\section{Statistical evaluation}

The study of association between the scoring group of each marker (absent/low or moderate/high expression for $\beta$-catenin, CD133 and CD166, and $\leq 5 \%$ or $>5 \%$ for Ki67) and clinico-pathological features (age, gender, recurrence and histotype) was carried out by Fisher's exact test. For pATM the population was divided into positive and negative cases.

Spearman correlation test was used to examine the correlation between $\beta$-catenin and, respectively, CD133, CD166 and Ki67 and between CD166 and Ki67.

A $p$ value $\leq 0.05$ was considered statistically significant. All tests were two sided and carried out with GraphPad Prism 5 software (GraphPad Software, La Jolla, CA, USA).

\section{Results}

\section{Clinicopathologic features}

Upon 45 patients (Table 1) 30 were males and 15 were females with mean age of 43 years (ranging from 2 to 77 years). Patients had been treated by surgical removal via endoscopic endonasaltransphenoidalsurgerythat wascomplete in 23 cases and subtotal in 22 cases; these latter received radiotherapy. In 38 cases the diagnosis was of adaCP and 7 cases werepapCP. Of 4 recurrent cases only the primary tumor tissue was included for statistical evaluation; in 9 cases only the tissue of the recurrence was available ( 8 adaCP and 1 papCP). Therefore 13 cases were considered recurrent tumors and 32 not.

\section{$\beta$-catenin immunostaining score correlated with recurrence}

All 45 cases were examined with $\beta$-catenin antibody. $\beta$ catenin immunoreactivity was detected at the cell membrane in most cases and in the nucleus in 28 cases. We focused on the nuclear signal that was located in neoplastic cells forming "whirl-like" structures and in palisading basal cells arranged around the stellate reticulum. The signal was variable in intensity and proportion of distribution (Fig. 1a-c).

$\beta$-catenin immunostaining score was negative in 17 cases and in positive cases it ranged from 1 to 9 , being $1,2,3,4,6$ and 9 in 4, 11, 2, 7, 3 and 1 cases, respectively. Based on the calculated IS, all specimens were subsequently divided into two different scoring groups: 32 


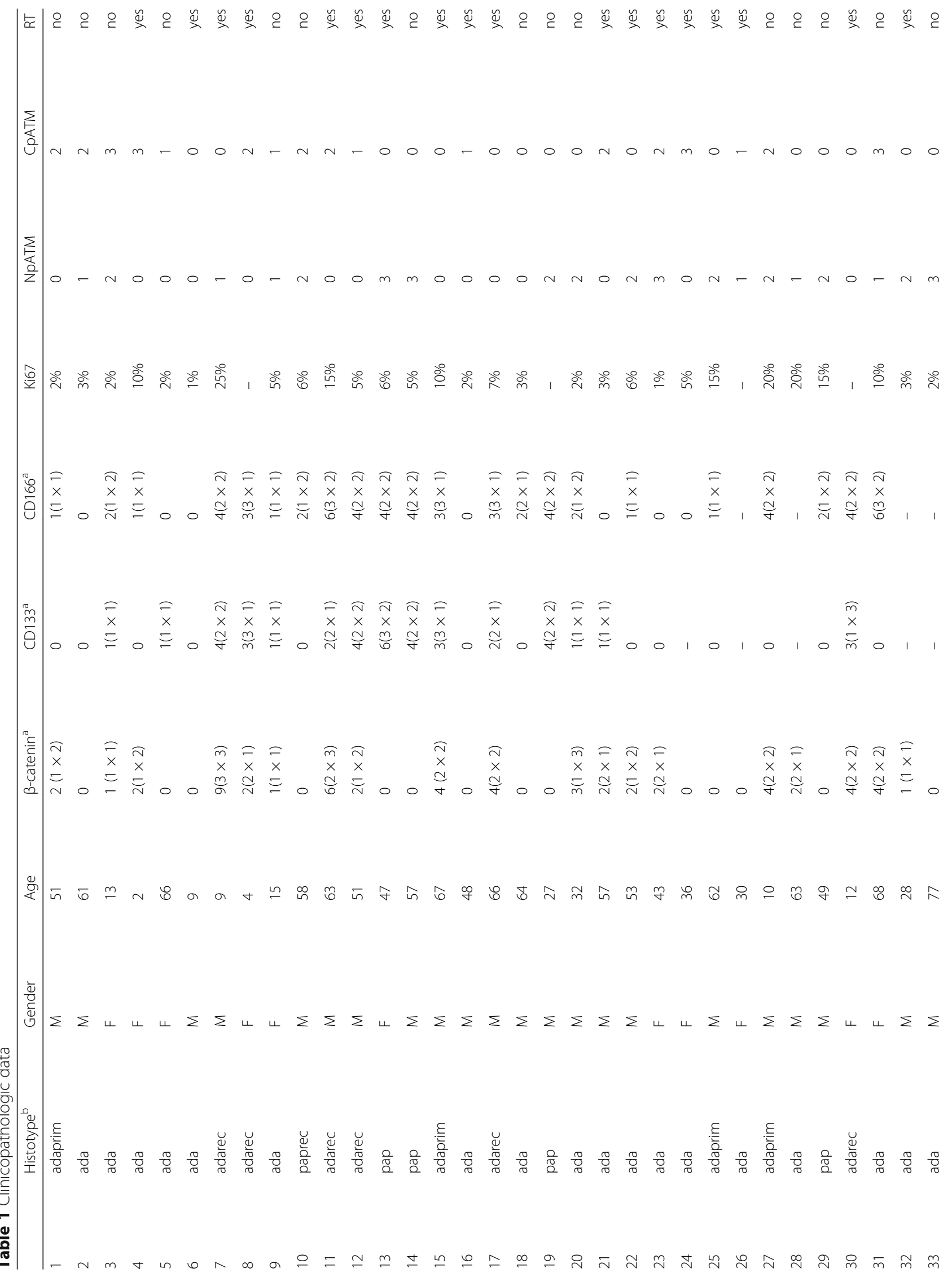




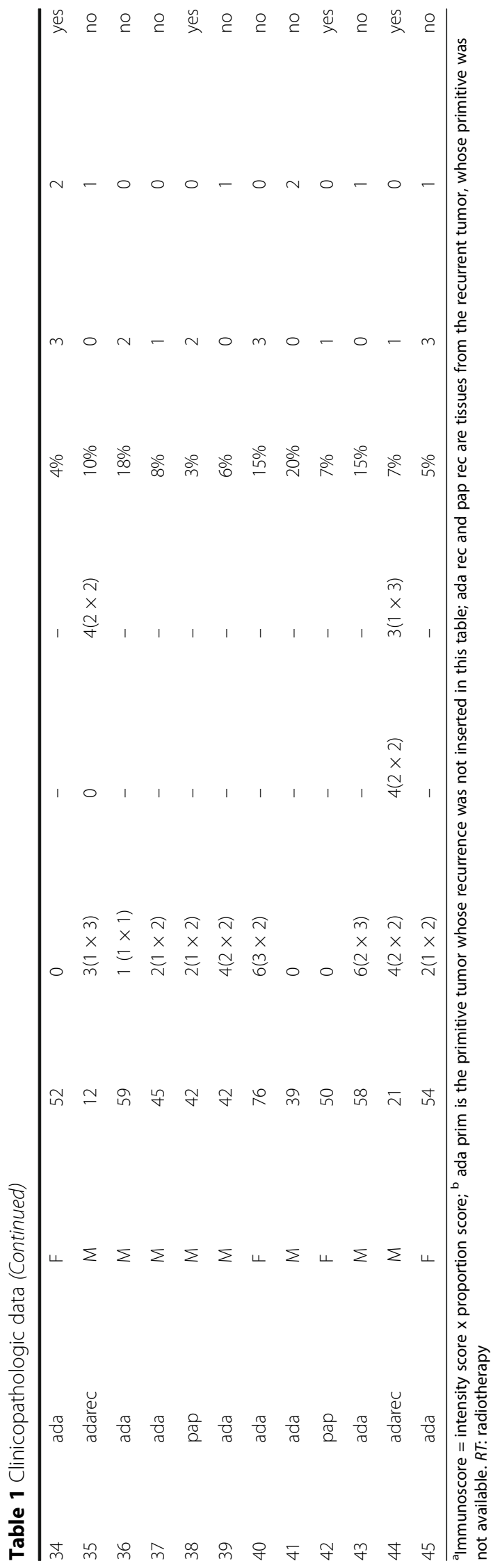




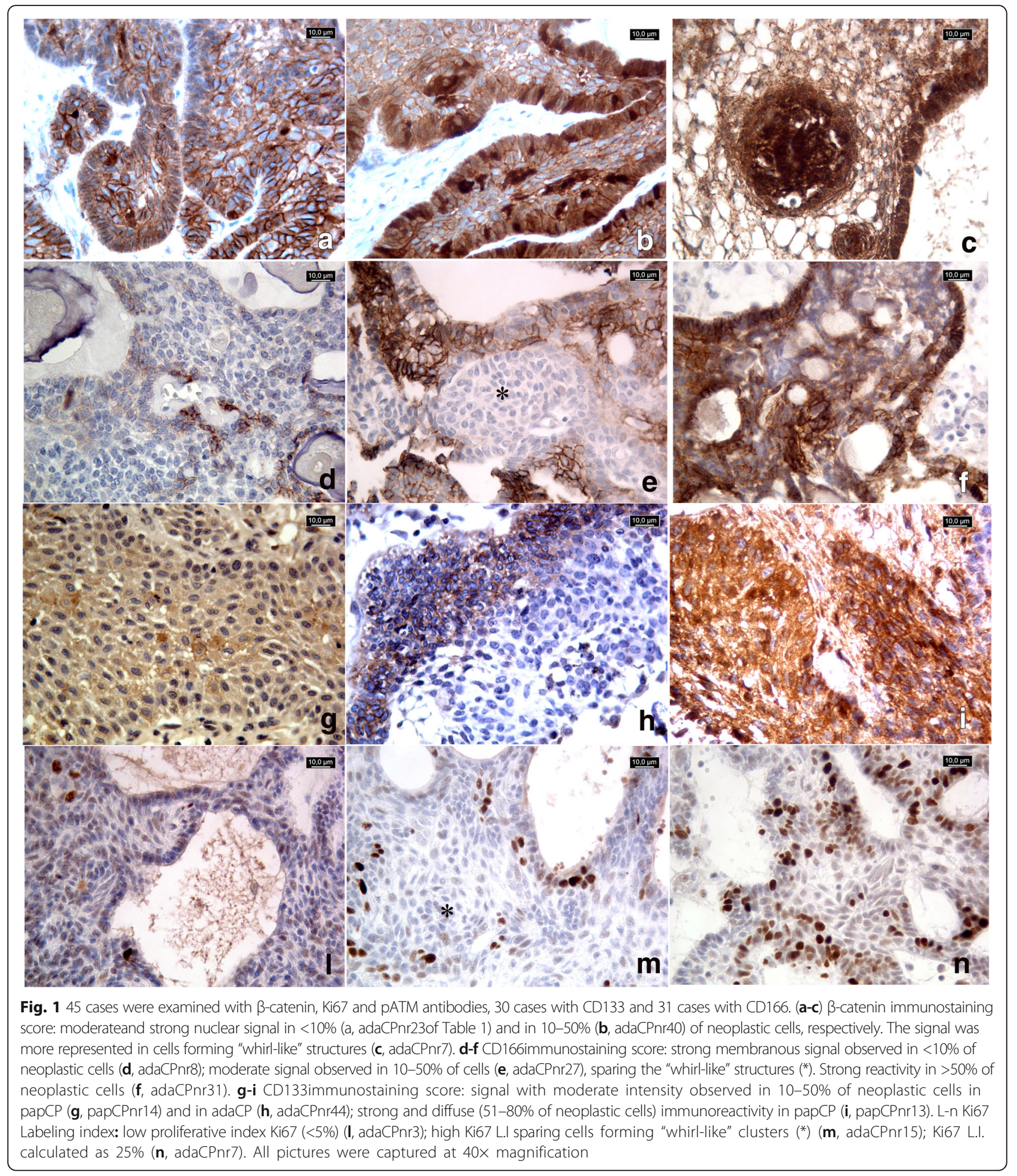

were absent/low (IS $=0-2)$ and 13 were moderate/high (IS > 2).

Out of 32 cases with absent/low $\beta$-catenin IS, 5 were recurrent, while out of 13 with moderate/high $\beta$-catenin IS, 8 were recurrent. Statistical analysis (Table 2) revealed the existence of a significant association between moderate/high $\beta$-catenin IS and recurrences in craniopharyngiomas $(p=0.0039)$. No other correlations with clinical variables (age, gender) were found out. A slight tendency to a higher expression of $\beta$-catenin was recorded for the adamantinomatoushistotype, rather than the papillary $(p=0.0895)$. In all 7 papCPs that were 
Table 2 Examination of correlation between clinical data and immunohistochemical scores

\begin{tabular}{|c|c|c|c|c|c|c|c|c|}
\hline \multirow[t]{2}{*}{ Variables } & $\begin{array}{l}\text { All cases } \\
\mathrm{N}=45\end{array}$ & $\begin{array}{l}\text { B-catenin } \\
\text { IS }\end{array}$ & & $p$ value & $\begin{array}{l}\text { All cases } \\
N=30\end{array}$ & CD133 IS & & $p$ value \\
\hline & (\%) & $0-2$ & $\geq 3$ & & (\%) & $0-2$ & $\geq 3$ & \\
\hline Gender & & & & 0.4917 & & & & 1.0000 \\
\hline Males & $30(67)$ & $20(62.5)$ & $10(77)$ & & $21(70)$ & $15(71)$ & $6(67)$ & \\
\hline Females & $15(33)$ & $12(37.5)$ & $3(23)$ & & $9(30)$ & $6(29)$ & $3(33)$ & \\
\hline Age & & & & 0.4113 & & & & 1.0000 \\
\hline$\leq 18 y$ & $9(20)$ & $5(16)$ & $4(31)$ & & $9(30)$ & $6(29)$ & $3(33)$ & \\
\hline$>18 y$ & $36(80)$ & $27(84)$ & $9(69)$ & & $21(70)$ & $15(71)$ & $6(67)$ & \\
\hline Histotype & & & & 0.0895 & & & & 0.1432 \\
\hline $\mathrm{adaCP}$ & $38(84)$ & $25(78)$ & $13(100)$ & & $25(83)$ & $19(90)$ & $6(67)$ & \\
\hline papCP & $7(16)$ & $7(22)$ & $0(0)$ & & $5(17)$ & $2(10)$ & $3(33)$ & \\
\hline Recurrence & & & & 0.0039 & & & & 0.1232 \\
\hline Yes & $13(29)$ & $5(16)$ & $8(62)$ & & $13(43)$ & $7(33)$ & $6(67)$ & \\
\hline No & $32(71)$ & $27(84)$ & $5(38)$ & & $17(57)$ & $14(67)$ & $3(33)$ & \\
\hline \multirow[t]{2}{*}{ Variables } & $\begin{array}{l}\text { All cases } \\
N=31\end{array}$ & $\begin{array}{l}\text { CD166 } \\
\text { IS }\end{array}$ & & $p$ value & $\begin{array}{l}\text { All cases } \\
N=41\end{array}$ & Ki67 L.I. & & $p$ value \\
\hline & (\%) & $0-2$ & $\geq 3$ & & (\%) & $0-2$ & $\geq 3$ & \\
\hline Gender & & & & 1.0000 & & & & 0.4926 \\
\hline Males & $21(68)$ & $11(65)$ & $10(71)$ & & $29(71)$ & $12(63)$ & $17(77)$ & \\
\hline Females & $10(32)$ & $6(35)$ & $4(29)$ & & $12(29)$ & $7(37)$ & $5(23)$ & \\
\hline Age & & & & 0.6927 & & & & 1.0000 \\
\hline$\leq 18 y$ & $9(29)$ & $4(31)$ & $5(36)$ & & $7(17)$ & $3(16)$ & $4(18)$ & \\
\hline$>18 y$ & $22(71)$ & $13(69)$ & $9(64)$ & & $34(83)$ & $16(84)$ & $18(82)$ & \\
\hline Histotype & & & & 0.6358 & & & & 0.6681 \\
\hline $\mathrm{adaCP}$ & $26(84)$ & $15(88)$ & $11(79)$ & & $35(85)$ & 17 (89) & $18(81)$ & \\
\hline papCP & $5(16)$ & $2(12)$ & $3(21)$ & & $6(15)$ & $2(11)$ & $4(19)$ & \\
\hline Recurrence & & & & 0.0040 & & & & 0.0385 \\
\hline Yes & $13(42)$ & $3(76)$ & $10(71)$ & & $11(27)$ & $2(10)$ & $9(41)$ & \\
\hline No & $18(58)$ & $14(24)$ & $4(29)$ & & $30(73)$ & $17(90)$ & 13(59) & \\
\hline
\end{tabular}

All statistcally significant findings were highlighted with bold

analyzed, $\beta$-catenin-IS was $\leq 2$ (6 cases were 0 and one was 2).

Ki67 immunostaining was available in 41 cases and it showed a mean value of $8 \%$ (median was $6 \%$, range1$25 \%)$. A statistically significant ( $p=0.0385)$ association between high Ki67 L.I. (>5\%) and recurrences was found but not as strong as with $\beta$-catenin IS. Cells forming "whirllike” clusters did not show high Ki67 L.I (Fig. 11-n).

\section{CD166 staining was not equally distributedthroughout the} adaCPtumor tissue and its IS was associated with recurrence CD166 was evaluated on 31 cases. The IS was negative in 7 cases and positive in 24 cases, ranging from 1 to 6 and being respectively 1,2, 3, 4 and 6 in 5, 5, 4,8 and 2 cases. 17 cases were assigned to the absent/low (IS =0-2) scoring group, while 14 to the moderate/high (IS > 2).

The signal was mainly located at the cell membrane (Fig. 1d-f) with diffuse distribution, howeversparing the whirl-like cell clusters, which showed nuclear $\beta$-catenin accumulations (Fig. 1e) in adaCPs. In papCPs the immunostainingappeared more homogeneous.

Out of 13 recurrent cases, 3 showed a CD166-IS $\leq 2$, while in 10 cases the immunoscore was $>2$. Fisher's exact test showed that CD166-IS was significantlyrelated with recurrence risk $(p=0.0040)$.

CD133 displayed membrane immunostaining with variable distribution (Fig. 1g-i) in both adaCPs and papCPs but its localization was not exclusively identified in cell clusters, as described in literature. 
No statistically significant associations between clinicopathologic variables (age, gender, histotype and recurrence) and CD133-IS were observed.

The Spearman test showed direct correlation between $\beta$-catenin and Ki67 ( $p=0.0011, r=0.4903), \beta$-catenin and CD166 $(p=0.0002, r=0.6218)$ and CD166 and Ki67 ( $p=0.0054, r=0.5119)$; no significant relation was disclosed between $\beta$-catenin and CD133 $(p=0.4156$, $r=0.1543)$.

\section{Cytoplasmic PATM was expressed significantly higher in adaCPcompared to papCP}

Twenty seven cases out of 45 showed nuclear expression of pATM (Fig. 2b): 9, 11 and 7 cases, each apart respectively with IS of 1,2 and 3 . All papCPs showed nuclear reactivity $(7 / 7)$.

In 23 out of 45 cases a cytoplasmic reactivity (Fig. 2a) was detected $(9,10$ and 4 cases showed 1,2 and 3 IS respectively). Only $1 / 7$ papCP and 16/28 adaCPs were positive.

We compared both pATM expressions, nuclear and cytoplasmic, in both CP subtypes, by Fisher's exact test and found out that NpATM was significantly more expressed in papCPs $(p=0.0313)$, while CpATM was more present in adaCPs $(p=0.0470)$ (Fig. 2c, d; Table 2 ). No differences were found out when we analyzed the different scoring groups (IS 1, 2 or 3).

Finally, we analyzed the likelihood of recurrence for papCPs, on the base of NpATM, and adaCP, on the base of CPATM; no statistically significant correlation was observed (Table 3).

\section{Discussion}

The unpredictable features and biological behavior, along with anatomical relationships that craniopharyngiomas establish, represent a key aspect to be considered to rule out prognosis and recurrence risk of these lesions.

$\beta$-catenin is a protein with a dual function, regulating cell-cell adhesion and gene transcription. It plays a key role in the Wnt signaling that is involved in morphogenesis and in the process of motility in adaCPs. It is known that exon3 deletion of CTNNB1 gene causes $\beta$-catenin intranuclear accumulation that can be highlighted by immunohistochemistry and, though it can represent a diagnostic hallmark.

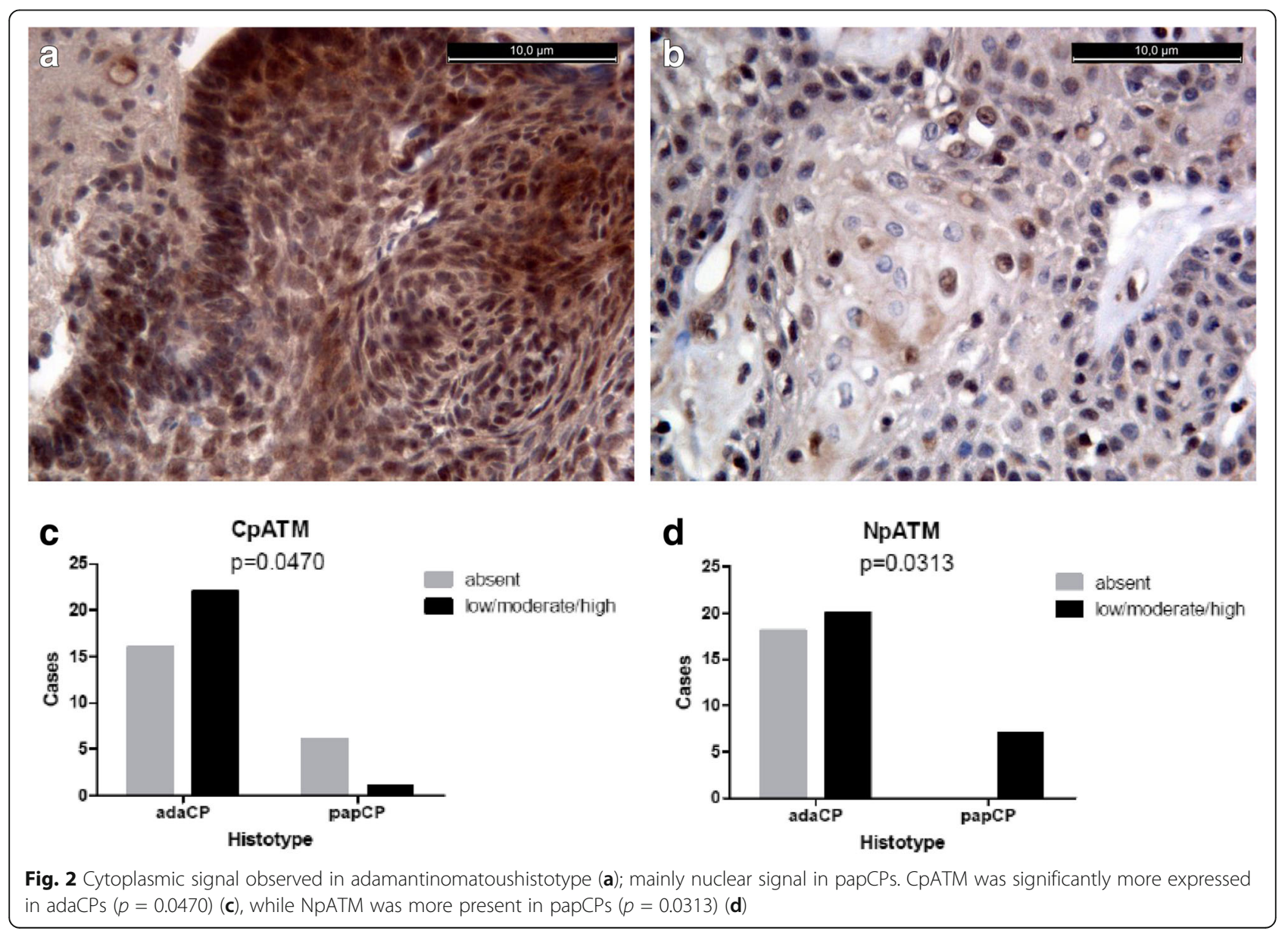


Table 3 Examination of correlation between clinical data and immunohistochemical scores

\begin{tabular}{|c|c|c|c|c|c|c|c|c|}
\hline \multirow[t]{2}{*}{ Variables } & \multirow{2}{*}{$\begin{array}{l}\text { All cases } \\
N=45 \\
(\%)\end{array}$} & \multicolumn{2}{|l|}{$\begin{array}{l}\text { NpATM } \\
\text { IS }\end{array}$} & \multirow[t]{2}{*}{$p$ value } & \multirow{2}{*}{$\begin{array}{l}\text { All cases } \\
N=45 \\
(\%)\end{array}$} & \multicolumn{2}{|l|}{$\begin{array}{l}\text { CPATM } \\
\text { IS }\end{array}$} & \multirow[t]{2}{*}{$\begin{array}{l}p \\
\text { value }\end{array}$} \\
\hline & & 0 & $1-3$ & & & 0 & $1-3$ & \\
\hline Gender & & & & 0.7477 & & & & 0.0574 \\
\hline Males & $30(67)$ & $13(72)$ & $17(63)$ & & $30(67)$ & $18(81)$ & $12(52)$ & \\
\hline Females & $15(33)$ & $5(28)$ & $10(37)$ & & $15(33)$ & $4(19)$ & $11(48)$ & \\
\hline Age & & & & 0.4487 & & & & 0.4591 \\
\hline$\leq 18 y$ & $9(20)$ & $5(28)$ & $4(15)$ & & $9(20)$ & $3(14)$ & $6(26)$ & \\
\hline$>18 y$ & $36(80)$ & $13(72)$ & $23(85)$ & & $36(80)$ & $19(86)$ & $17(74)$ & \\
\hline Histotype & & & & 0.0313 & & & & 0.0470 \\
\hline $\mathrm{adaCP}$ & $28(80)$ & $18(100)$ & $20(74)$ & & $38(84)$ & $16(73)$ & $22(96)$ & \\
\hline papCP & $7(20)$ & $0(0)$ & $7(26)$ & & $7(16)$ & $6(27)$ & $1(4)$ & \\
\hline Recurrence $^{a}$ & & & & 1.0000 & & & & 1.0000 \\
\hline Yes & $1(14)$ & $0(0)$ & $1(17)$ & & $12(32)$ & $8(32)$ & $4(31)$ & \\
\hline No & $6(86)$ & $1(100)$ & $5(83)$ & & $26(68)$ & $17(68)$ & $9(69)$ & \\
\hline
\end{tabular}

${ }^{a}$ Recurrence was evaluated only among papCP for NpATM and only among adaCP for CpATM

All statistcally significant findings were highlighted with bold

In our study we examined the nuclear expression of $\beta$-catenin in adaCP specimens from 45 patients and investigated the association between the signal and recurrence risk. We found out that a moderate/high signal was more often detected in recurrent tumors.

Probably this could be related to the role of cotranscription factor: indeed, when inside the nucleus, $\beta$-catenin binds transcriptional activators, switching on target genes [24].

Furthermore, Wnt signaling and the elevated level of $\beta$-catenin are involved in the maintenance of pluripotency in many cell types [25]. Few studies focused the attention on the presence of a stem cell component among CPs $(10,11)$ : some authors supposed that $\beta$ catenin accumulating cell clusters could be part of a stem cell niche and may contribute to tumor recurrence. We showed that a medium/high average number of clusters is associated with a higher recurrence rate, whether their sporadic presence is not enough. On the contrary, the relationship with stem cells is not clear: we noted that CD166 correlates with $\beta$-catenin and the presence of recurrence, whilst the opposite aspect was seen for CD133.

CD166 is an activated leukocyte cell adhesion molecule (ALCAM), with a controversial role in cancer: immunohistochemical studies on melanocytic lesions showed that CD166 overexpression was associated with tumor progression [26], as well as in bladder cancer with stage/grade [27] and in esophageal squamous cell carcinoma with poor prognosis [28]. In breast cancer, instead, reduced expression of ALCAM was associated with poor prognosis [29]. Moreover, it was shown that human colorectal and prostate cancer stem cells were characterized by the expression of this adhesion molecule [30, 31].

In our series, we observed that CD166 was expressed in CPs and it showed a membrane signal whose immunoscore correlated with $\beta$-catenin, Ki67 and recurrence risk. It remains unclear whether it behaves as a stem cell marker in CPs: though, it seems to spare the whirl-like cell clusters in adaCPs, where there should be the stem cell niches. However, regardless of its role in stemness, it can be of help, together with $\beta$-catenin, to predict recurrences in CPs. In our cohort CD133 was expressed in both histotypes, while it was described to be almost undetectable in papCPs (11).

Many other markers of stemness (SOX9, SOX2, CD44, NANOG, etc) have been studied in pituitary lesions and, curiously, in adaCP, SOX9 nuclear immunostaining was observed not only in the palisaded basal cell layer of the epithelium, but also in the stellate stromal cells under the epithelium [32]. The same authors also found a correlation between relapse and a high expression level of SOX9. In our series we did not find reactivity of CD133 nor of CD166 in the stellate stromal cells under the epithelium, but only throughout it, just like other markers that had been studied by Chang et al. Therefore, we could hypotize that SOX9 is a marker of progenitor mesenchymal stem cells and represents a more precocius marker of stemness whose higher expression influences the tumor behavior (eg relapse).

The potential of $\mathrm{Ki} 67$ as prognostic marker was confirmed. A cut-off of $5 \%$ was established as a valid tool to effectively distinguish highly proliferative forms from those with a low rate of proliferation. The Labeling Index was calculated on cells other than 
those of the basal layer where a high proliferative activity was expected.

Our results could weigh in on the need of a prognostic algorithm for the management of craniopharyngiomas: the identification of a batch of prognostic factors, indeed, could be helpful to determine a more appropriate integrated therapeutic modality.

As well, pATM expression was assessed in the attempt of identifying potential factors that can affect radiosensitivity in CPs. This kinase has a specific role in the DNA double-strand breaks repair, that is exercised in the nucleus, and a cytoplasmic function that is related to autophagy [33], a process that may be implied in therapy resistance [34].

In our series, we observed mainly a nuclear signal in papCPs and a cytoplasmic in adaCs: this allowed us to consider that pATM different expression patterns in $\mathrm{CP}$ subtypes might be used as additional diagnostic and prognostic tool. No predictive role of recurrence was observed for pATM, neither cytoplasmic nor nuclear.

The prevalent cytoplasmic localization of pATM in adaCPs may be the effect of a different pathogenetic role of this kinase in the two histotypes. Further studies are needed to clear this aspect.

\section{Conclusions}

In modern histopathology there is a strong need to identify prognostic markers able to predict at best the biology of tumors. In craniopharyngiomas recurrence is an event that should be managed and prevented with multidisciplinary approach, in order to define the most appropriate treatment strategy. Overall, our results demonstrate how $\beta$-catenin, CD166 and Ki67 could be a valid supplementary tool. They can be also regarded as potentially useful antitumor targets.

Furthermore, our findings could suggest to introduce pATM as additional distinction-marker between adamantinomatous and papillary histotypes.

\section{Abbreviations \\ adaCP: Adamantinomatous craniopharyngiomas; ALCAM: Activated leukocyte cell adhesion molecule; CD133: Cluster of differentiation 133; CD166: Cluster of differentiation 166; CpATM: Cytoplasmic phospho-ATM; CTNNB1: Catenin Beta 1; IS: Immunostaining score; L.I: Labeling index; NpATM: Nuclear PATM; papCP: Papillary craniopharyngiomas; p-ATM: Phosphorilated- Ataxia- Telangiectasia mutated; WHO: World Health Organization; WNT: Wingless type}

\section{Acknowledgments}

All the authors have substantively contributed to the realization of the manuscript and gave permission to be named. No person not named in the manuscript has made substantial contributions to this manuscripts to warrant inclusion in the Acknowledgments. No fundings to declare.

\section{Funding}

No funding was received.

\section{Availability of data and materials}

Data are stored by the corresponding author of this paper and are available upon request.

\section{Authors' contributions \\ EG: participated in the acquisition and evaluation of the data, wrote the manuscript and prepared the figures; OdD: participated in the manuscript drafting; DS: conducted surgery and participated in the manuscript drafting; BG: performed immunohistochemistry; UMB: participated in the evaluation of the data; ADS: participated in the acquisition of data and in the project design; PC: conducted surgery and supervised the manuscript; MDBDC: participated in the evaluation of the data, in the project design and in the supervision of the manuscript. All authors reviewed the manuscript. All authors read and approved the final manuscript.}

\section{Ethics approval and consent to participate}

This was a retrospective study with tissue samples retrieved from the archives of our Institute. For each patient a written informed consent to use part of the specimen for scientific and/or research scopes was available. Therefore, the project was not submitted to a named institutional and/or licensing committee.

\section{Consent for publication}

Not applicable.

Competing interests

None to declare.

\section{Publisher's Note}

Springer Nature remains neutral with regard to jurisdictional claims in published maps and institutional affiliations.

\section{Author details}

${ }^{1}$ Department of Advanced Biomedical Sciences, Pathology Section, University of Naples Federico II, Via Pansini 5, 80131 Naples, Italy. ${ }^{2}$ Department of Neurosciences, Reproductive and Odontostomatological Sciences, Division of Neurosurgery, University of Naples Federico II, Via Pansini 5, 80131 Naples, Italy. ${ }^{3}$ Department of Public Health, Unit of Vascular and Endovascular Surgery, University of Naples Federico II, Via Pansini 5, 80131 Naples, Italy.

Received: 3 March 2017 Accepted: 25 June 2017

Published online: 14 July 2017

\section{References}

1. Louis DN, Ohgaki H, Wiestler OD, Cavenee WK. WHO classification of tumours of the central nervous system. Lyon: Int Agency Res. 4th Edition revised, 2016.

2. Clark AJ, Cage TA, Aranda D, Parsa AT, Sun PP, Auguste Kl, et al. A systematic review of the results of surgery and radiotherapy on tumor control for pediatric craniopharyngioma. Childs Nerv Syst. 2013;29:231-8.

3. Sartoretti-Schefer S, WichmannW AA, Valavanis A. MR differentiation of adamantinomatous and squamous-papillary craniopharyngiomas. AJNR Am J Neuroradiol. 1997;18:77-87.

4. Sekine S, Shibata T, Kokubu A, Morishita Y, Noguchi M, Nakanishi Y, et al. Craniopharyngiomas of adamantinomatous type harbor beta-catenin gene mutations. Am J Pathol. 2002;161:1997-2001.

5. Hölsken A, Kreutzer J, Hofmann BM, Hans V, Oppel F, Buchfelder M, et al. Target gene activation of the Wnt signaling pathway in nuclear betacatenin accumulating cells of adamantinomatous craniopharyngiomas. Brain Pathol. 2009;19:357-64.

6. Buslei R, Nolde M, Hofmann B, Meissner S, Eyupoglu IY, Siebzehnrübl F, et al. Common mutations of beta-catenin in adamantinomatous craniopharyngiomas but not in other tumours originating from the sellar region. Acta Neuropathol. 2005;109:589-97.

7. Brastianos PK, Taylor-Weiner A, Manley PE, Jones RT, Dias-Santagata D, Thorner AR, et al. Exome sequencing identifies BRAF mutations in papillary craniopharyngiomas. Nat Genet. 2014;46:161-5.

8. Brastianos PK, Santagata S. ENDOCRINE TUMORS: BRAF V600E mutations in papillary craniopharyngioma. Eur J Endocrinol. 2016;174:R139-44. 
9. Harada N, Tamai Y, Ishikawa T, Sauer B, Takaku K, Oshima M, et al. Intestinal polyposis in mice with a dominant stable mutation of the beta-catenin gene. EMBO J. 1999;18:5931-42.

10. Martinez-Barbera JP. Molecular and cellular pathogenesis of adamantinomatous craniopharyngioma. Neuropathol Appl Neurobiol. 2015; 41:721-32.

11. Hölsken A, Stache C, Schlaffer SM, Flitsch J, Fahlbusch R, Buchfelder M, et al. Adamantinomatous craniopharyngiomas express tumor stem cell makers in cells with activated Wnt signaling: further evidence for the existence of a tumor stem cell niche? Pituitary. 2014;17:546-56.

12. Yaşargil MG, Curcic M, Kis M, Siegenthaler G, Teddy PJ, Roth P. Total removal of craniopharyngiomas. Approaches and long-term results in 144 patients. J Neurosurg. 1990;73:3-11.

13. Cavallo LM, Prevedello DM, Solari D, Gardner PA, Esposito F, Snyderman CH, et al. Extended endoscopic endonasal transsphenoidal approach for residual or recurrent craniopharyngiomas. J Neurosurg. 2009;111:578-89.

14. Cavallo LM, Frank G, Cappabianca P, Solari D, Mazzatenta D, Villa A, et al. The endoscopic endonasal approach for the management of craniopharyngiomas: a series of 103 patients. J Neurosurg. 2014;121:100-13.

15. Weiner HL, Wisoff JH, Rosenberg ME, Kupersmith MJ, Cohen H, Zagzag D, et al. Craniopharyngiomas: a clinicopathological analysis of factors predictive of recurrence and functional outcome. Neurosurgery. 1994;35: 1001-10.

16. Samii M, Samii A. Surgical management of craniopharyngiomas. In: Schmidek HH, ed. Schmidek \& Sweet Operative neurosurgical techniques. Indications, methods and results. Philadelphia: W. B. Saunders; 2000;1:489-502.

17. Prieto R, Pascual JM, Subhi-Issa I, Jorquera M, Yus M, Martínez R. Predictive factors for craniopharyngioma recurrence: a systematic review and illustrative case report of a rapid recurrence. World Neurosurg. 2013;79:733-49.

18. Wu B, Sun C, Feng F, Ge M, Xia L. Do relevant markers of cancer stem cells CD133 and Nestin indicate a poor prognosis in glioma patients? A systematic review and meta-analysis. J Exp Clin Cancer Res. 2015;34:44.

19. Kaur S, Singh G, Kaur K. Cancer stem cells: an insight and future perspective. J Cancer Res Ther. 2014;10:846-52.

20. Zhang W, Chen H, Lv S, Yang H. High CD133 expression is associated with worse prognosis in patients with Glioblastoma. Mol Neurobiol. 2016;53: 2354-60.

21. Guadagno E, Borrelli G, Califano M, Calì G, Solari D, Del Basso De Caro M Immunohistochemical expression of stem cell markers CD44 and nestin in glioblastomas: evaluation of their prognostic significance. Pathol Res Pract. 2016;212:825-32.

22. Eom DW, Hong SM, Kim G, Bae YK, Jang KT, Yu E. Prognostic significance of CD44v6, CD133, CD166, and ALDH1 expression in small intestinal adenocarcinoma. Appl Immunohistochem Mol Morphol. 2015;23:682-8.

23. Lee JH, Paull TT. Activation and regulation of ATM kinase activity in response to DNA double-strand breaks. Oncogene. 2007;26:7741-8.

24. Novak A, Dedhar S. Signaling through beta-catenin and Lef/Tcf. Cell Mol Life Sci. 1999:56:523-37.

25. Sokol SY. Maintaining embryonic stem cell pluripotency with Wnt signaling. Development. 2011;138:4341-50.

26. van Kempen LC, van den Oord JJ, van Muijen GN, Weidle UH, Bloemers HP, Swart GW. Activated leukocyte cell adhesion molecule/CD166, a marker of tumor progression in primary malignant melanoma of the skin. Am J Pathol. 2000;156:769-74.

27. Ofori-Acquah SF, King JA. Activated leukocyte cell adhesion molecule: a new paradox in cancer. Transl Res. 2008;151:122-8.

28. Verma A, Shukla NK, Deo SV, Gupta SD, Ralhan R. MEMD/ALCAM: a potentia marker for tumor invasion and nodal metastasis in esophageal squamous cell carcinoma. Oncology. 2005;68:462-70.

29. King JA, Ofori-Acquah SF, Stevens T, Al-Mehdi AB, Fodstad O, Jiang WG. Activated leukocyte cell adhesion molecule in breast cancer: prognostic indicator. Breast Cancer Res. 2004:6:R478-87.

30. Dalerba P, Dylla SJ, Park IK, Liu R, Wang X, Cho RW, et al. Phenotypic characterization of human colorectal cancer stem cells. Proc Natl Acad Sci U S A. 2007;104:10158-63.

31. Rajasekhar VK, Studer L, Gerald W, Socci ND, Scher HI. Tumour-initiating stem-like cells in human prostate cancer exhibit increased NF-kappa B signalling. Nat Commun. 2011;2:162
32. Chang CV, Araujo RV, Cirqueira CS, Cani CM, Matushita H, Cescato VA, et al. Differential expression of stem cell markers in human Adamantinomatous Craniopharyngioma and pituitary adenoma. Neuroendocrinology. 2017;104: 183-93.

33. Alexander A, Cai SL, Kim J, Nanez A, Sahin M, KH ML, et al. ATM signals to TSC2 in the cytoplasm to regulate mTORC1 in response to ROS. Proc Natl Acad Sci U S A. 2010;107:4153-8.

34. Yan Y, Xu Z, Dai S, Qian L, Sun L, Gong Z. Targeting autophagy to sensitive glioma to temozolomide treatment. J ExpClin Cancer Res. 2016;35:23.

\section{Submit your next manuscript to BioMed Central and we will help you at every step:}

- We accept pre-submission inquiries

- Our selector tool helps you to find the most relevant journal

- We provide round the clock customer support

- Convenient online submission

- Thorough peer review

- Inclusion in PubMed and all major indexing services

- Maximum visibility for your research

Submit your manuscript at www.biomedcentral.com/submit 